Key Words:

Mixing, MST,

CST, Sludge,

SCIX

Retention:

Permanent

\title{
Pilot-Scale Testing of the Suspension of MST, CST, and Simulated Sludge Slurries in a Sludge Tank
}

\author{
Michael R. Poirier \\ Zafar H. Qureshi \\ Michael L. Restivo \\ Timothy J. Steeper \\ Michael R. Williams \\ David T. Herman
}

August 2, 2011

Savannah River National Laboratory

Savannah River Nuclear Solutions

Aiken, SC 29808

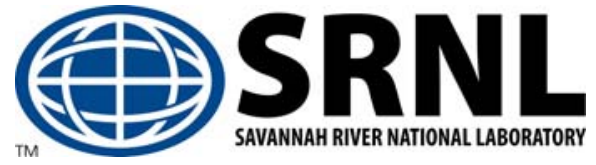




\section{DISCLAIMER}

This work was prepared under an agreement with and funded by the U.S. Government. Neither the U. S. Government or its employees, nor any of its contractors, subcontractors or their employees, makes any express or implied:

1. warranty or assumes any legal liability for the accuracy, completeness, or for the use or results of such use of any information, product, or process disclosed; or

2. representation that such use or results of such use would not infringe privately owned rights; or

3. endorsement or recommendation of any specifically identified commercial product, process, or service.

Any views and opinions of authors expressed in this work do not necessarily state or reflect those of the United States Government, or its contractors, or subcontractors.

Printed in the United States of America

Prepared for

U.S. Department of Energy 


\section{REVIEWS AND APPROVALS}

\section{Authors}

M. R. Poirier, SRNL, Advanced Characterization \& Processing

Date

Z. H. Qureshi, SRNL, Engineering Development Laboratory

Date

M. L. Restivo, SRNL, Engineering Development Laboratory

Date

T. J. Steeper, SRNL, Engineering Development Laboratory

Date

M. R. Williams, SRNL, Engineering Development Laboratory

Date

D. T. Herman, SRNL, Advanced Characterization \& Processing

Date

\section{Design Check}

C. A. Nash, SRNL, Advanced Characterization \& Processing

Date

\section{Management}

F. M. Pennebaker, Manager, SRNL, Advanced Characterization \& Processing $\quad$ Date

S. L. Marra, Manager, SRNL, E\&CPT Research Programs

Date

Customer

T. H. Huff, Manager, SRR, Small Column Ion Exchange Program

Date 


\section{TABLE OF CONTENTS}

LIST OF ACRONYMS .................................................................................................... iv

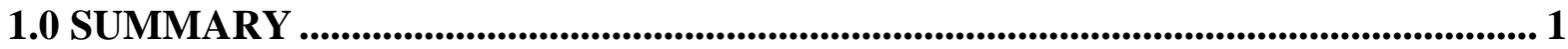

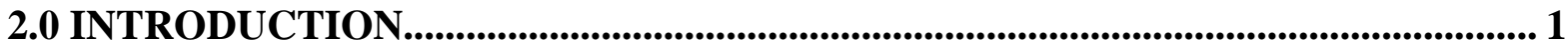

3.0 TEST EQUIPMENT AND TESTING DESCRIPTION .................................................... 2

3.1 PILOT SCALE TEST FACILITY DESCRIPTION....................................................... 2

3.2 EXPERIMENTAL STEPS - RESUSPENSION TESTS ................................................ 6

3.3 EXPERIMENTAL STEPS - TALL COLUMN .............................................................. 8

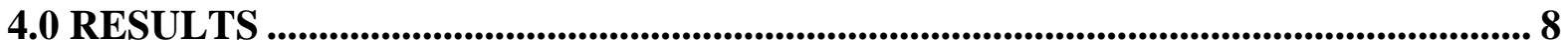

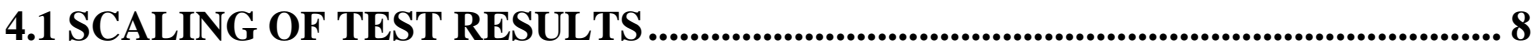

4.2 INITIAL MIXING AND SETTLING .............................................................................. 8

4.3 SOLIDS RESUSPENSION TEST WITH THREE PUMPS ....................................... 12

4.4 SOLIDS RESUSPENSION TEST WITH FOUR PUMPS ........................................ 13

4.5 TALL COLUMN TEST .................................................................................................... 15

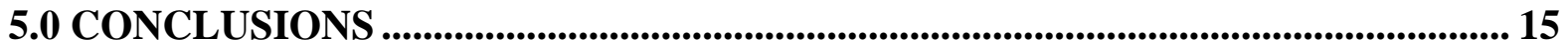

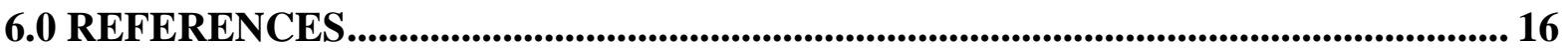




\section{LIST OF ACRONYMS}

$\begin{array}{ll}\text { ARP } & \text { Actinide Removal Process } \\ \text { CST } & \text { Crystalline Silicotitanate } \\ \text { DWPF } & \text { Defense Waste Processing Facility } \\ \text { EDL } & \text { Engineering Development Laboratory } \\ \text { gpm } & \text { Gallons per minute } \\ \text { MST } & \text { Monosodium Titanate } \\ \text { P\&ID } & \text { Process and Instrument Diagram } \\ \text { PNNL } & \text { Pacific Northwest National Laboratory } \\ \text { RMF } & \text { Rotary Microfilter } \\ \text { rpm } & \text { revolutions per minute } \\ \text { RMJ } & \text { Rotating Mixer Jet } \\ \text { SCIX } & \text { Small Column Ion Exchange } \\ \text { SDIP } & \text { Salt Disposition Integration Project } \\ \text { SRNL } & \text { Savannah River National Laboratory } \\ \text { SRR } & \text { Savannah River Remediation } \\ \text { SRS } & \text { Savannah River Site } \\ \text { VFD } & \text { Variable Frequency Drive } \\ \text { VSL } & \text { Vitreous State Laboratory }\end{array}$




\subsection{SUMMARY}

The Small Column Ion Exchange (SCIX) process is being developed to remove cesium, strontium, and actinides from Savannah River Site (SRS) Liquid Waste using an existing waste tank (i.e., Tank $41 \mathrm{H}$ ) to house the process. Following strontium, actinide, and cesium removal, the concentrated solids will be transported to a sludge tank (i.e., monosodium titanate (MST)/sludge solids to Tank $42 \mathrm{H}$ or Tank $51 \mathrm{H}$ and crystalline silicotitanate (CST) to Tank 40H) for eventual transfer to the Defense Waste Processing Facility (DWPF). Savannah River National Laboratory (SRNL) is conducting pilot-scale mixing tests to determine the pump requirements for mixing MST, CST, and simulated sludge. The purpose of this pilot scale testing is to determine the pump requirements for mixing MST and CST with sludge in a sludge tank and to determine whether segregation of particles occurs during settling. Tank $40 \mathrm{H}$ and Tank 51H have four Quad Volute pumps; Tank 42H has four standard pumps.

The pilot-scale tank is a $1 / 10.85$ linear scaled model of Tank $40 \mathrm{H}$. The tank diameter, tank liquid level, pump nozzle diameter, pump elevation, and cooling coil diameter are all 1/10.85 of their dimensions in Tank 40H. The pump locations correspond to the current locations in Tank 40H (Risers B2, H, B6, and G). The pumps are pilot-scale Quad Volute pumps. Additional settling tests were conducted in a 30 foot tall, 4 inch inner diameter clear column to investigate segregation of MST, CST, and simulated sludge particles during settling.

The conclusions from this analysis follow:

- If MST, CST, and simulated sludge particles are well mixed in a sludge tank prior to settling, no preferential settling or segregation is observed over four weeks at $45^{\circ} \mathrm{C}$.

- Four Quad Volute pumps have the power to disperse MST and CST in sludge that has been mixed.

- Four Quad Volute pumps provide the power needed to mix and resuspend MST, CST, and simulated sludge solids that settle for four weeks at $45^{\circ} \mathrm{C}$ in a sludge tank.

- The ability of pumps to disperse MST and CST with sludge is a strong function of the sludge shear strength and yield stress. An increase in shear strength or yield stress leads to an increase in the $\mathrm{U}_{0} \mathrm{D}$ needed to mix the slurry. A decrease in shear strength or yield stress leads to a decrease in the $\mathrm{U}_{0} \mathrm{D}$ needed to mix the slurry.

- The tall column test showed no evidence of segregation or preferential settling of the MST and CST particles.

\subsection{INTRODUCTION}

Savannah River Remediation (SRR) is developing the SCIX process to remove cesium, strontium, and select actinides from SRS Liquid Waste using an existing waste tank (i.e., Tank $41 \mathrm{H}$ ) to house the process. The process adds MST as a slurry to the waste tank (i.e., Tank $41 \mathrm{H}$ ) to chemically sorb the strontium and select actinides, removes the MST and entrained sludge with in-riser rotary microfilters (RMF), and removes cesium from the RMF filtrate with ion-exchange columns containing CST. The RMFs return the concentrated solids (i.e., MST and entrained sludge) to the waste tank. After being loaded with cesium, the CST is ground to reduce its size and transferred as a slurry to Tank $40 \mathrm{H}$ (baseline case). The MST and 
sludge in the waste tank (i.e., Tank $41 \mathrm{H}$ ) will be periodically transported to a sludge batch preparation tank (Tank $42 \mathrm{H}$ or Tank $51 \mathrm{H}$ ). Both the MST and CST streams will ultimately be transferred to the DWPF for vitrification.

To assist SRR in designing the SCIX process, SRNL is conducting pilot-scale testing to determine the number, type, and size of pumps needed to mix and resuspend MST and CST particles with sludge particles in DWPF preparation tanks (i.e., Tank 40H, Tank 42H, and Tank $51 \mathrm{H}) .{ }^{1}$ The objective of this testing is not to determine pump requirements for mixing sludge in sludge preparation tanks.

This document describes the pump requirements to mix MST and CST with sludge as they are added to a sludge tank and resuspend MST, CST, and simulated sludge slurries (in the ratios expected in Tank $40 \mathrm{H}$ ) that have settled for four weeks at nominal $45^{\circ} \mathrm{C}$.

Previous documents ${ }^{2,3}$ describe the tests conducted to determine the pump requirements to suspend MST, CST, and simulated sludge in the SCIX process tank (i.e., Tank $41 \mathrm{H}$ ) with and without settling for four weeks at nominal $45^{\circ} \mathrm{C}$.

\subsection{TEST EQUIPMENT AND TESTING DESCRIPTION}

\subsection{PILOT SCALE TEST FACILITY DESCRIPTION}

To meet the above objectives, SRNL personnel designed, fabricated, and assembled a 1/10.85 scale type IIIA waste tank in the Engineering Development Laboratory (EDL). The main tank is a nominal 8 foot diameter, 41 inch high transparent acrylic tank of wall thickness 1 inch. The pilot-scale tank contains cooling coils, which were fabricated from $1 / 4$ inch stainless steel tubing ( 0.25 inch outside diameter) and linearly scaled to the diameter of the cooling coils in Tank $41 \mathrm{H}$. The coils were arranged to replicate the cooling coils in Tank $41 \mathrm{H}$. ${ }^{\mathrm{b}}$ The acrylic tank sits on a 38 inch high open steel stand. This design facilitated direct visual observation of the cleaning radius from underneath since the tank bottom is transparent. At the center of the tank, a stainless steel center column is provided. A false bottom is provided to keep the tank contents heated to $45^{\circ} \mathrm{C}$ for prolonged periods while the tank contents are settling. For more details on fabrication of the pilot-scale tank, see reference [2]. A photograph of the clear tank with scaled Tank $41 \mathrm{H}$ cooling coils is shown in Figure 1.

\footnotetext{
a Temperature $=45 \pm 5^{\circ} \mathrm{C}$

${ }^{\mathrm{b}}$ Reviewing drawings W700991 (Tank 40H Cooling Coils) and W701081 (Tank 41H Cooling Coils) shows the cooling coil arrangement to be similar in Tank $40 \mathrm{H}$ and Tank $41 \mathrm{H}$. The use of the Tank $41 \mathrm{H}$ cooling coil arrangement in this test rather than the Tank $40 \mathrm{H}$ cooling coil arrangement would not have a significant impact on the fluid motion in the tank.
} 


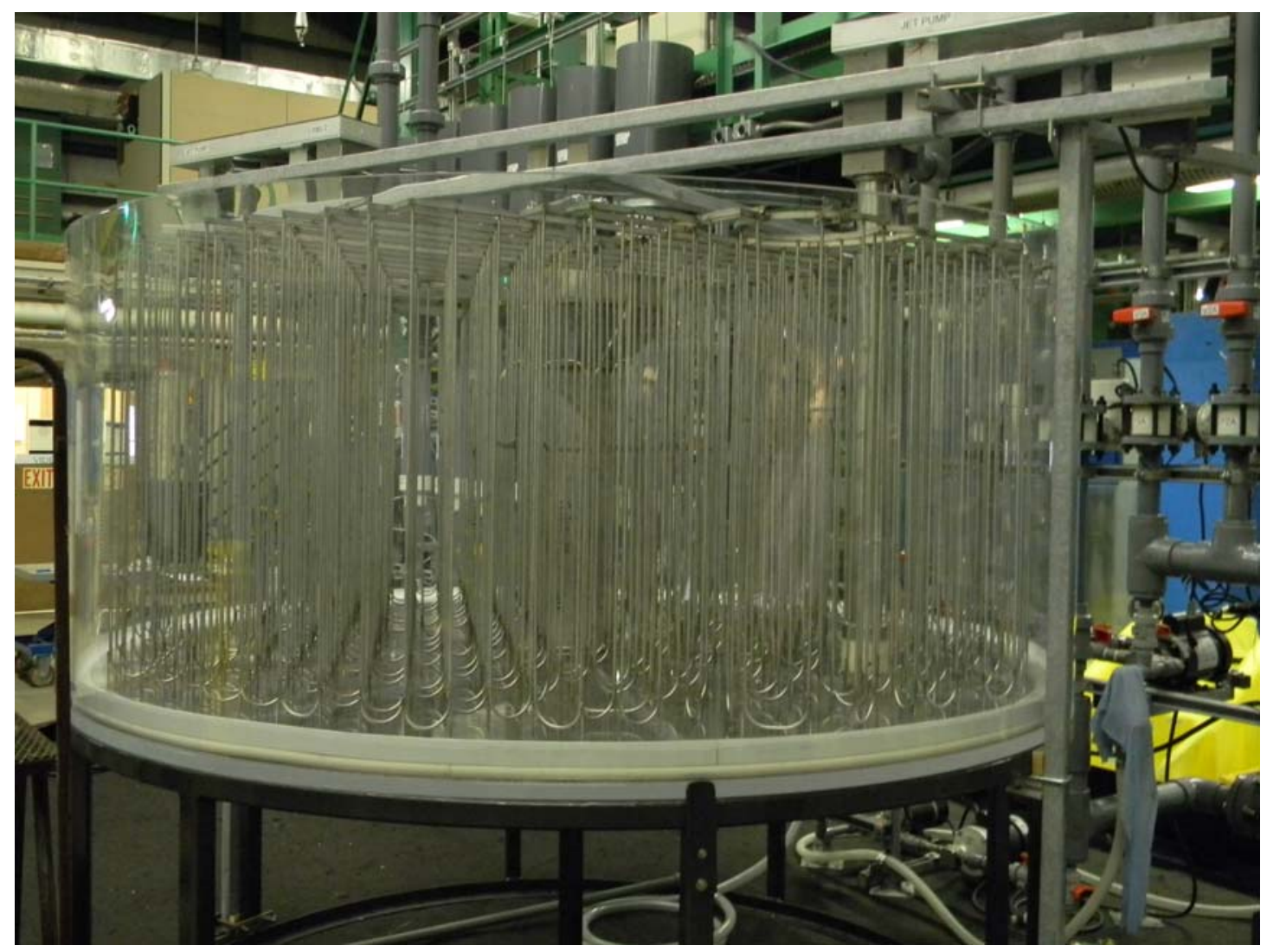

Figure 1. Pilot-Scale Waste Tank

Figure 2 shows a top view of the pilot-scale tank with Tank $41 \mathrm{H}$ coils. Note that the current test applies to Tank $40 \mathrm{H}$ using four Quad Volute pumps. Thus, in Figure 2, Tank $40 \mathrm{H}$ risers are superimposed on the Tank $41 \mathrm{H}$ coil and riser configuration. Tank $40 \mathrm{H}$ risers are shown in red. It can be seen that Tank 40H risers B2, H, B6, and G closely match four Tank 41H riser locations. Based on this, it was decided to use the locations shown in Figure 2 for the placement of four mixing pumps M1, M2, M3, and M4.

The black line segments show the cooling coils. Green lines show the drive mechanisms for the four mixing pumps. 


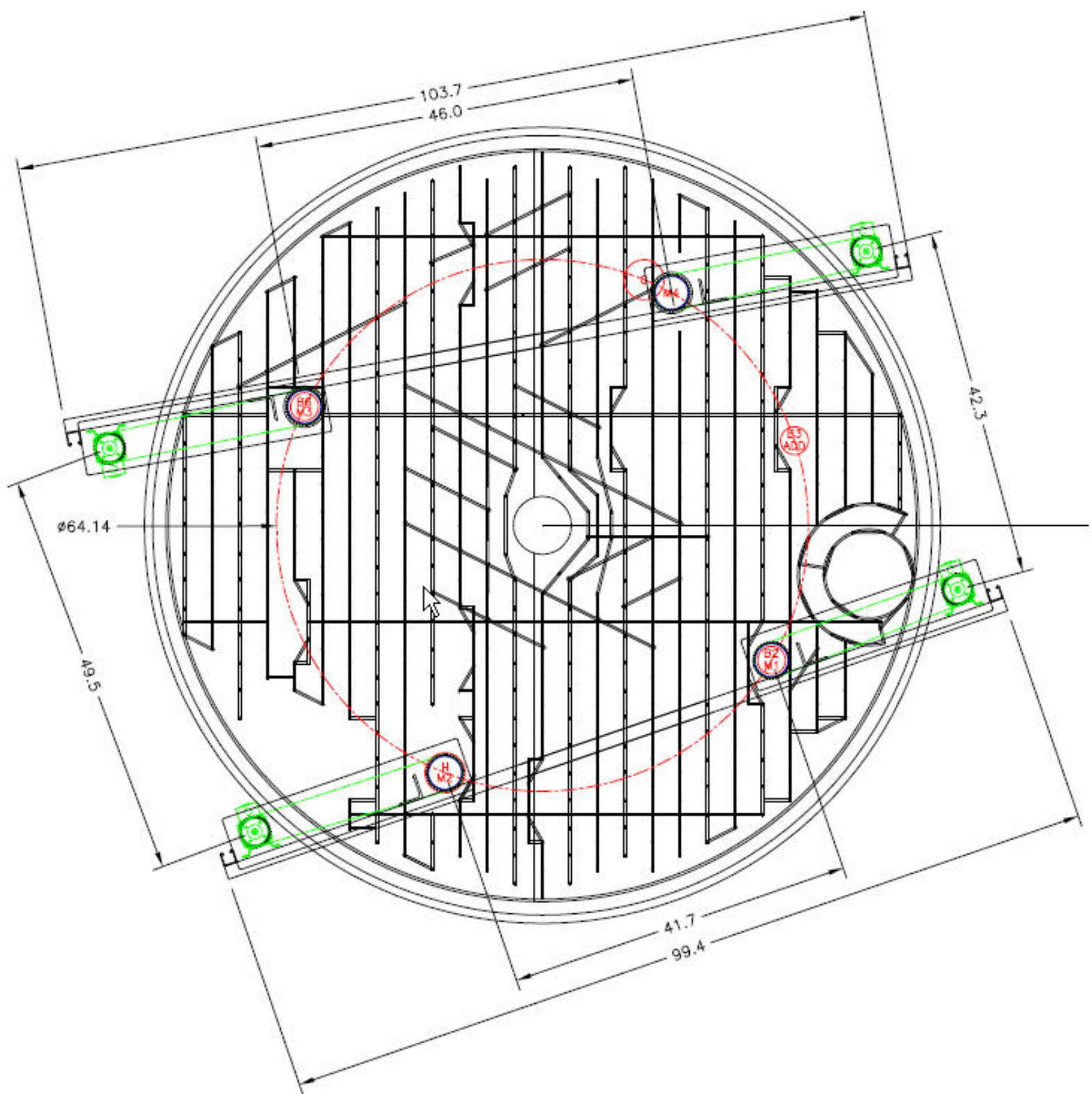

Figure 2. Pilot-Scale Tank Top View

Personnel placed three radial lines extending from each of the pumps on the tank bottom (see Figure 3). One of the lines from each pump extended from the pump to the center column. The other two lines extended from the pump to the tank wall, reaching the wall at the point corresponding to the midpoint between the pump and the closest pump on that side of the tank. The maximum cleaning radius needed to completely suspend the solid particles with four pumps is 36 inches in the pilot-scale tank (32.6 feet in Tank 40H). 


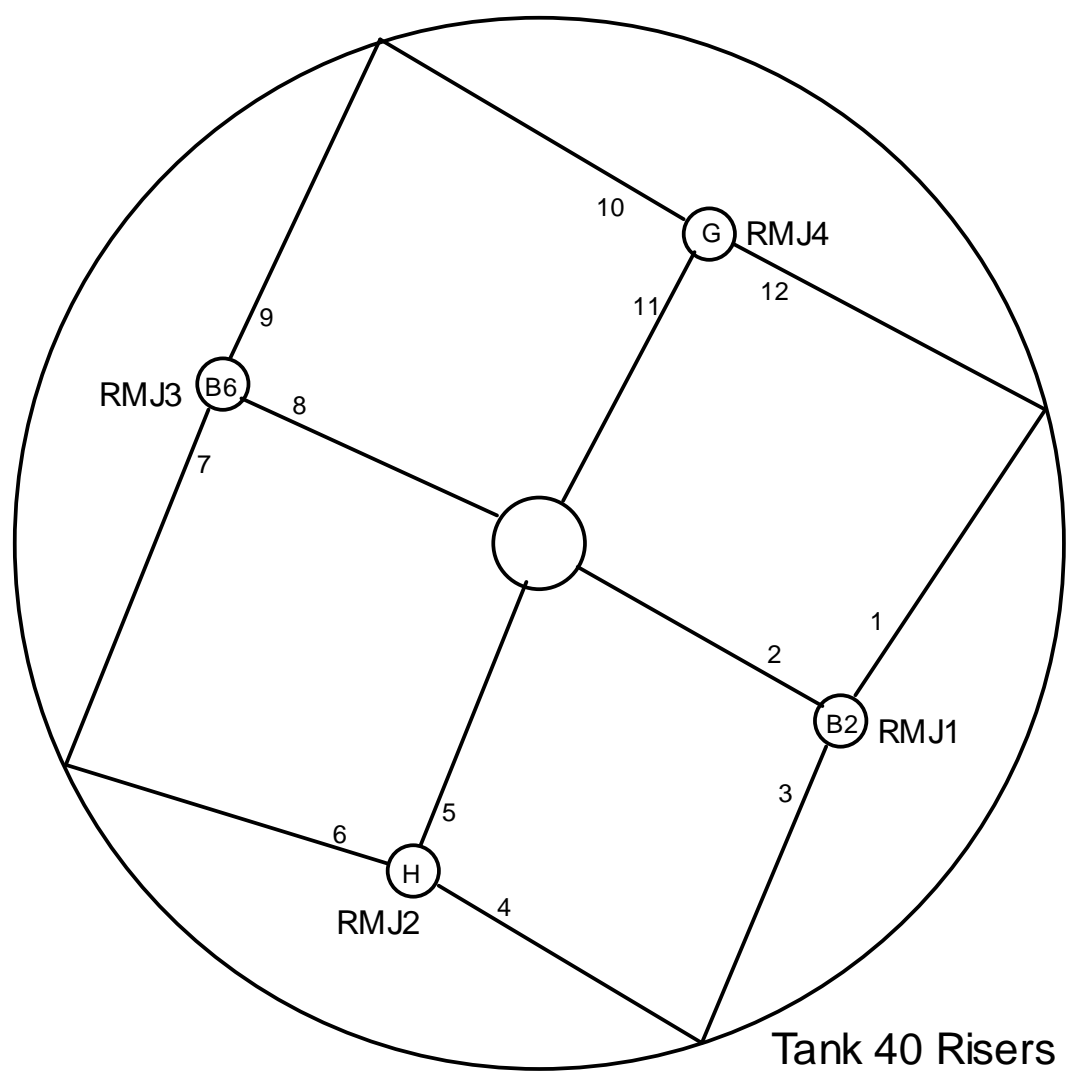

Figure 3. Cleaning Radius Measurement Locations for Four Pump Configuration

Figure 4 shows the process and instrumentation diagram (P\&ID) for the Pilot-Scale Test Facility. It schematically shows the mixing tank, four mixer pumps, the external recirculation pump for mixers, and the instrumentation to measure flow rates and process temperatures. The tank heating system is also shown. The heating fluid in the false bottom is circulated independently by a separate pump through a 6700 watt heater. The fluid temperature at the heater outlet is measured to control the heater, which turns on or off as needed. For the settling and resuspension tests, the temperature was controlled to $45 \pm 5{ }^{\circ} \mathrm{C}$. The main circulation pump is controlled by a variable frequency drive (VFD) controller. This controller varies the main pump motor speed to achieve different flow rates through the mixer pumps. Additional flow balancing in the mixer pump is achieved by throttling a valve in each flow path.

Two additional vane type pumps are also provided for chemical transfers in and out of the tank. These vane pumps are also used to prime the centrifugal pump and vent the air out of the flow loop.

The nozzle diameters are linearly scaled to the actual pumps. All tests were conducted with scaled Quad Volute pumps. Details on the pump assembly and stainless steel pump heads are provided in a previous technical report. ${ }^{2}$ 


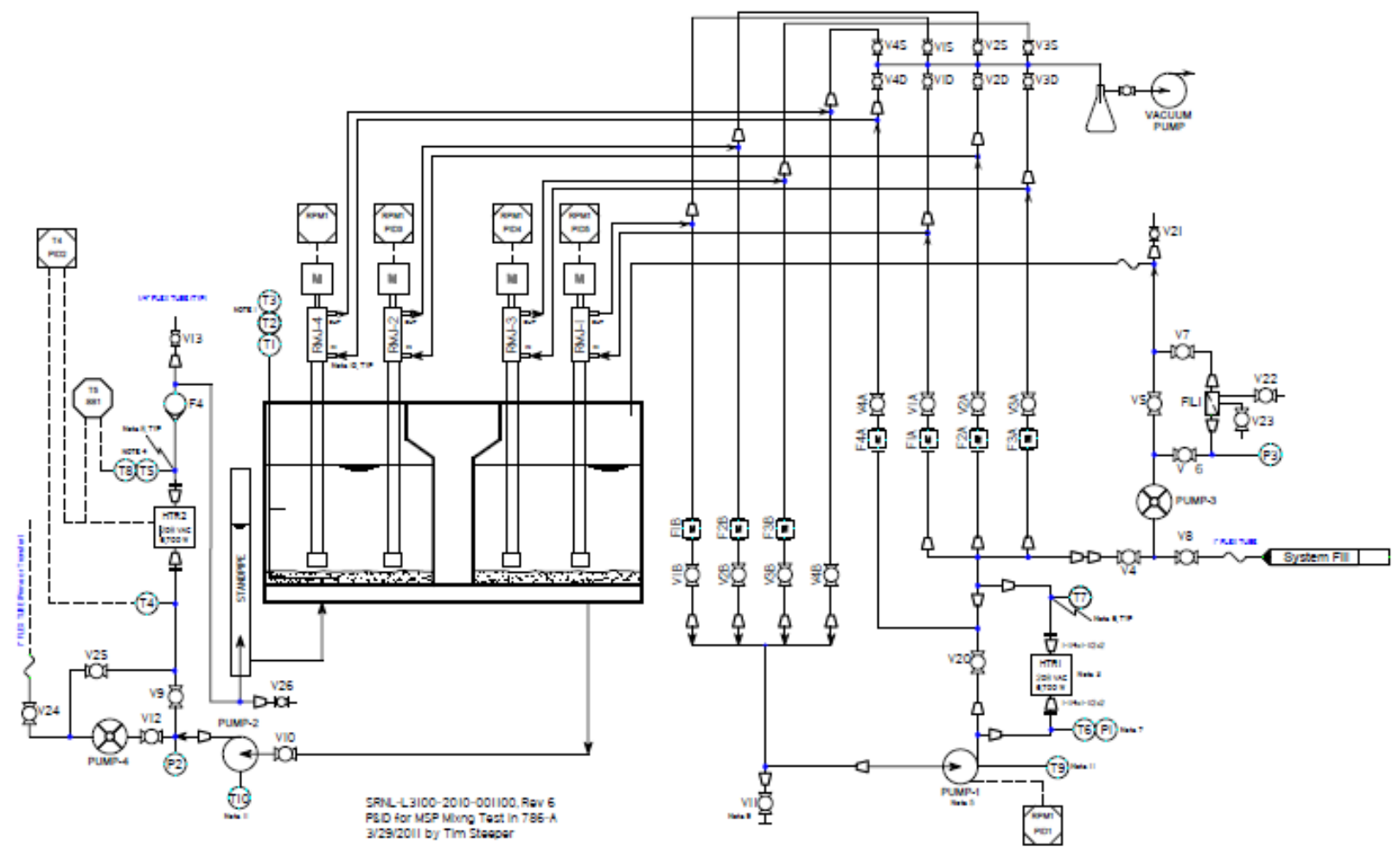

Figure 4. Process and Instrumentation Diagram of Pilot Scale Test Facility

The fluid coming out the nozzles is parallel to the tank bottom as in Tank $40 \mathrm{H}$. The flow rate to each mixer pump is proportional to the jet velocity at the discharge point. The discharge velocity is the most important parameter for resuspension of solids in the tank. It can be calculated using Equation (1) below

$$
\mathrm{U}_{0}=4 \mathrm{Q} / \pi \mathrm{D}^{2}
$$

where $\mathrm{U}_{0}$ is the average pump nozzle discharge velocity, $\mathrm{Q}$ is the flow rate through the pump nozzle, and $\mathrm{D}$ is the nozzle diameter. Additionally, the mixer pumps are designed to rotate the pump heads. For the present tests, all mixing pump heads were rotated at 3.6 revolutions per minute (rpm) (for basis, see reference 3). The nozzle orientation for different heads was not synchronized. Instead, it was kept at a random orientation to mimic prototypic conditions.

\subsection{EXPERIMENTAL STEPS - RESUSPENSION TESTS}

Pilot-scale resuspension tests were performed in the following manner. The feed tank was filled with 110 gallons of simulated sludge ${ }^{c}$ by adding sludge to the premeasured mark in the tank. To this sludge, 55 gallons of simulated, washed Tank $37 \mathrm{H}$ supernate was added (see Table 1).

\footnotetext{
c The 110 gallons is based on 140,000 gallons (approximately 40 inches) of sludge in Tank 40H.
} 
Table 1. Simulated Supernate Solution Recipe

\begin{tabular}{lll}
\cline { 1 - 1 } Ionic Species & & Washed Tank 37F $(\mathrm{M})$ \\
$\mathrm{NO}_{3}^{+}$ & & 1.0 \\
$\mathrm{NO}_{2}^{-}$ & 0.35 \\
$\mathrm{OH}^{-}$ & 0.11 \\
$\mathrm{AlO}_{2}^{-}$ & 0.40 \\
$\mathrm{CO}_{3}^{-2}$ & 0.054 \\
$\mathrm{SO}_{4}^{-2}$ & 0.017 \\
$\mathrm{SiO}_{3}^{-2}$ & 0.023 \\
& $0.0006^{-2}$
\end{tabular}

The sludge and washed supernate slurry were mixed with four scaled Quad Volute pumps for 30 minutes at a flow rate of approximately $27 \mathrm{gpm}$ per pump (1.38 $\mathrm{ft}^{2} / \mathrm{s}$ for each nozzle). After mixing the slurry, personnel added 74.6 grams of MST and mixed the slurry with four scaled Quad Volute pumps for 30 minutes at a flow rate of approximately $25 \mathrm{gpm}$ per pump (1.27 $\mathrm{ft}^{2} / \mathrm{s}$ for each nozzle). After mixing the slurry, personnel added 1260 grams of CST and mixed the slurry with four scaled Quad Volute pumps for 30 minutes at a flow rate of approximately 25 gpm per pump (1.27 $\mathrm{ft}^{2} / \mathrm{s}$ for each nozzle). Using a correlation developed by SRNL for jet mixing in waste tanks with cooling coils ${ }^{4}$, the calculated mixing time is approximately six minutes. The researchers mixed for 30 minutes to ensure the sludge and supernate were well mixed.

Table 2 shows the amounts of MST, CST, and sludge added (on a slurry basis). The MST was from the same batch being used at the Actinide Removal Process (ARP) and provided by SRR. It was a 15 wt \% slurry with a median particle size of 16 micron. The CST (IE-911) was manufactured by UOP and ground by the Vitreous State Laboratory (VSL) using a Hockmeyer immersion mill (planned grinding technology for SCIX). It was a $20 \mathrm{wt} \%$ slurry with a median particle size of $2.5-8.2$ micron. The sludge was simulated Sludge Batch 6. It was a $10.5 \mathrm{wt} \%$ insoluble solids slurry produced by Optima ${ }^{5}$, and had a median particle size of 23 micron.

Table 2. Amounts of MST, CST, and Simulated Sludge Added to the Pilot-Scale Tank

Test

Amount MST (15 wt \% slurry)

Amount CST (20 wt \% slurry)

Amount Sludge (10.35 wt \% slurry)
MST+CST+Sludge

$495 \mathrm{~g}$

$6290 \mathrm{~g}$

$466 \mathrm{~kg}$

The solids (MST, CST, and simulated sludge) were allowed to settle for four weeks at $45 \pm 5{ }^{\circ} \mathrm{C}$. Following the settling, the mixer pumps were operated at increasing flow rates and the cleaning radius was measured at each flow rate. Researchers measured the cleaning radius along each of three radial lines extending from each pump (see Figure 3). At each pump flow rate, researchers allowed 10 minutes for the cleaning radius to reach steady-state. In some instances, they allowed longer to reach steady-state. Initially, the tank was mixed with three pumps (RMJ-1, RMJ-2, and RMJ-4) to evaluate the impact of a pump failure on the process of dispersing the MST and CST in a sludge tank. Following the attempt to mix the sludge with three pumps, the tank was mixed with four pumps. The recorded cleaning radius was the minimum of the measured values that

\footnotetext{
${ }^{\mathrm{d}}$ Based on SRS average salt solution
} 
were less than the distance to the wall or center column. The flow rate was increased until all solid particles were resuspended, the maximum pump flow rate was reached, or increased flow would not support removal of additional material.

\subsection{EXPERIMENTAL STEPS - TALL COLUMN}

The authors performed a tall column settling test with a 4 inch diameter, 30 foot high clear column that was used in the Salt Disposition Integration Project (SDIP) mixing tests. ${ }^{6}$ To perform this test, they collected 13.1 gallons $(55.5 \mathrm{~kg}$ ) of simulated Sludge Batch 6 (see reference 5 for recipe), 58.9 grams of MST (15 wt \% slurry), and 749 grams of CST (20 wt \% slurry). The ratio of MST:CST:Sludge was 1:17:660, the same ratio used in the rheology tests. ${ }^{7}$ These slurries were mixed and added to the tall column. The initial height of the slurry was 20 feet. The material settled for four weeks at ambient temperature.

\subsection{RESULTS}

\subsection{SCALING OF TEST RESULTS}

The pilot-scale results must be applied to the full-scale waste tanks. The scaling of test results from pilot-scale to full-scale is described in another SRNL document. ${ }^{8}$ Since the sludge level in this test (and in Tank 40H) is above the pump discharge nozzle rather than a thin layer on the tank bottom, sludge mixing is controlled by normal jet forces impacting the sludge rather than a shear stress at the tank bottom. ${ }^{8,9,10}$ The approach is described in references 8,9 , and 10 , and by equation [2]

$$
\mathrm{U}_{0 \text {-full-scale }}=\mathrm{U}_{0 \text {-pilot-scale }}
$$

where $\mathrm{U}_{0}$ is the nozzle discharge velocity. The nozzle discharge velocity is the same at both scales. This scaling differs from the scaling of solids suspension in salt tanks. In those tanks, the suspension and resuspension is controlled by shear stresses at the tank bottom. ${ }^{8}$ In sludge tanks, the mixing and solids dispersion is controlled by normal forces between the pump jet and the sludge. ${ }^{9,10}$ The cooling coils will cause less drag and less reduction in jet velocity in the fullscale tank compared with the pilot-scale tank. ${ }^{8}$ Therefore, the recommended pump nozzle velocity in the full-scale tank contains some conservatism.

The pump rotation rate in the pilot-scale tests should be 10.85 times the pump rotation rate in the full-scale tank. ${ }^{8}$ Given typical pump rotation rates in the SRS Tank Farms are 1/5 - 1/3 rpm, the pump rotation rate in these tests was $3.6 \mathrm{rpm}(0.33 \mathrm{rpm} * 10.85=3.6 \mathrm{rpm})$.

\subsection{INITIAL MIXING AND SETTLING}

Prior to the start of testing, personnel filled the tank with water and turned on the pumps to determine the maximum flow rate (and nozzle discharge velocity) that could be achieved. The maximum liquid flow rate through a single pump was $38 \mathrm{gpm}(69.5 \mathrm{ft} / \mathrm{s}$ nozzle discharge velocity). This flow rate is $97 \%$ of the maximum flow rate of a Quad Volute pump. 
After filling the tank with simulated sludge and supernate, four pumps were operated at approximately $27 \mathrm{gpm}$ per pump (49.5 ft/s, $\left.1.38 \mathrm{ft}^{2} / \mathrm{s}\right)$. The pump discharge velocity was approximately $70 \%$ of the maximum discharge velocity of a Quad Volute pump. The sludge and supernate were mixed for approximately 30 minutes. The simulated sludge and supernate appeared to be well mixed. The sludge and supernate may have been well mixed at a lower $\mathrm{U}_{0} \mathrm{D}$, but data was not collected at a lower pump flow rate. The pump $\mathrm{U}_{0} \mathrm{D}$ was $113 \%$ of the maximum $\mathrm{U}_{0} \mathrm{D}$ of a standard pump, so four standard pumps may be able to mix the sludge and supernate.

The ability of a pump to mix the sludge and supernate depends on the yield stress and shear strength of the sludge. If the yield stress and shear strength of the sludge are decreased, the required $\mathrm{U}_{0} \mathrm{D}$ is decreased. If the yield stress and shear strength of the sludge are increased, the required $\mathrm{U}_{0} \mathrm{D}$ is increased.

With four pumps running at approximately 25 gpm per pump (45.8 ft/s, $\left.1.27 \mathrm{ft}^{2} / \mathrm{s}\right)$, MST was added to the tank. The pump discharge velocity was approximately $65 \%$ of the maximum discharge velocity of a Quad Volute pump. The tank was mixed for approximately 30 minutes. The MST was dispersed by the mixing in the tank.

With the pumps running at approximately 25 gpm per pump, CST was added to the tank. The tank was mixed for approximately 30 minutes. The CST was dispersed by the mixing in the tank.

The MST and CST were mixed and dispersed in the sludge at a pump $\mathrm{U}_{0} \mathrm{D}$ that corresponds to $65 \%$ of the maximum $\mathrm{U}_{0} \mathrm{D}$ of a Quad Volute pump. The sludge, MST, and CST may have been well mixed at a lower $\mathrm{U}_{0} \mathrm{D}$, but data was not collected at a lower pump flow rate. The pump $\mathrm{U}_{0} \mathrm{D}$ was $104 \%$ of the maximum $\mathrm{U}_{0} \mathrm{D}$ of a standard pump, so four standard pumps would be marginal for dispersing the CST with the sludge and MST.

During the mixing of the MST and CST with the sludge, no segregation of the MST and CST from the sludge was observed. After settling overnight at $45^{\circ} \mathrm{C}$, the sludge color appeared uniform. No "white streaks" were observed as was seen in previous rheology tests. ${ }^{7}$ One white spot approximately $1 \mathrm{~cm}^{2}$ was observed on the tank bottom. Individual white particles were observed near Pump 3. Around the tank wall, liquid was observed between the sludge on the tank bottom and the sludge at the surface (see Figure 5). The likely cause of this phenomenon is the sludge "sticking" to the tank wall and cooling coils. After approximately 2.5 weeks, the sludge sank to the tank bottom (see Figure 6). A few spots were observed, but no gross segregation was observed. Table 3 shows the number of spots $(<1 / 4$ inch) observed in each octant of the tank (see Figure 7) after settling for four weeks at $45^{\circ} \mathrm{C}$. Figure 8 shows spots on the tank bottom observed after settling for four weeks. Figure 9 shows pictures of depth samples collected from the tank after settling for four weeks. No particle segregation is observed in these samples. 


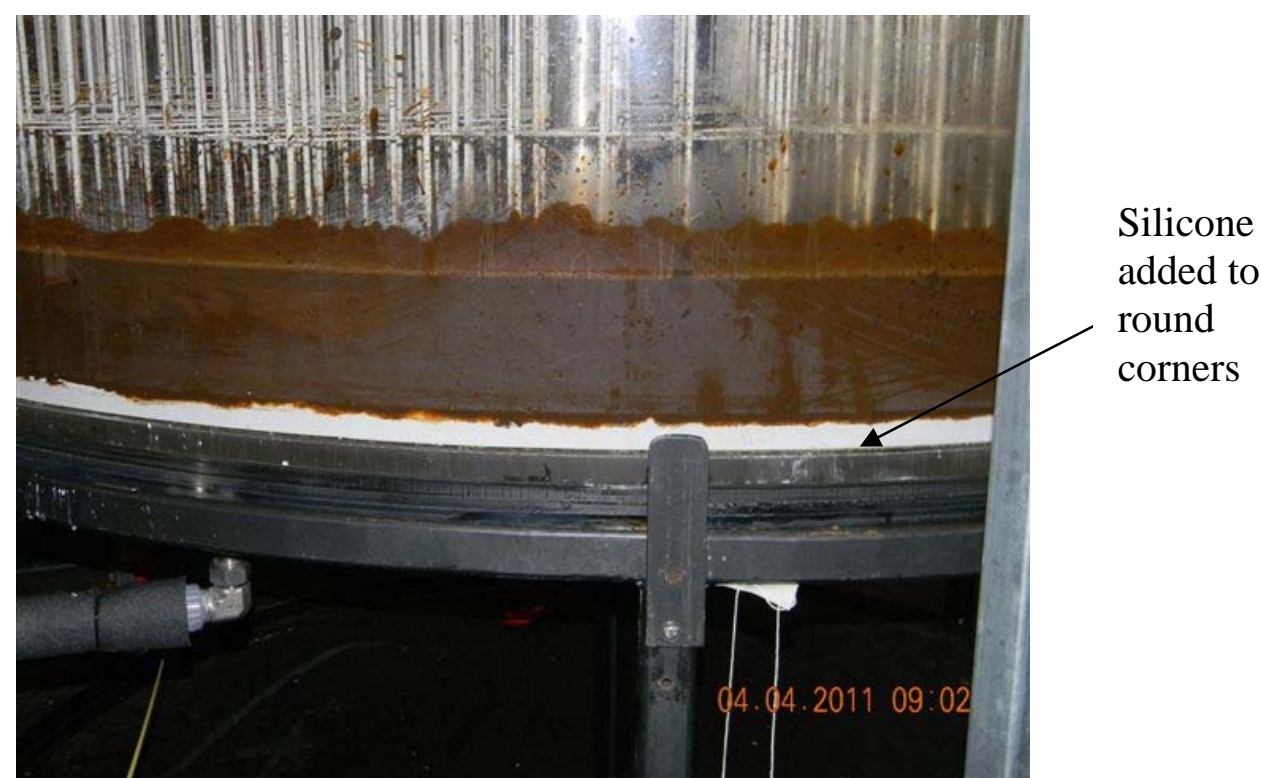

Figure 5. Liquid Layer Between Settled Solids in Pilot-Scale Tank

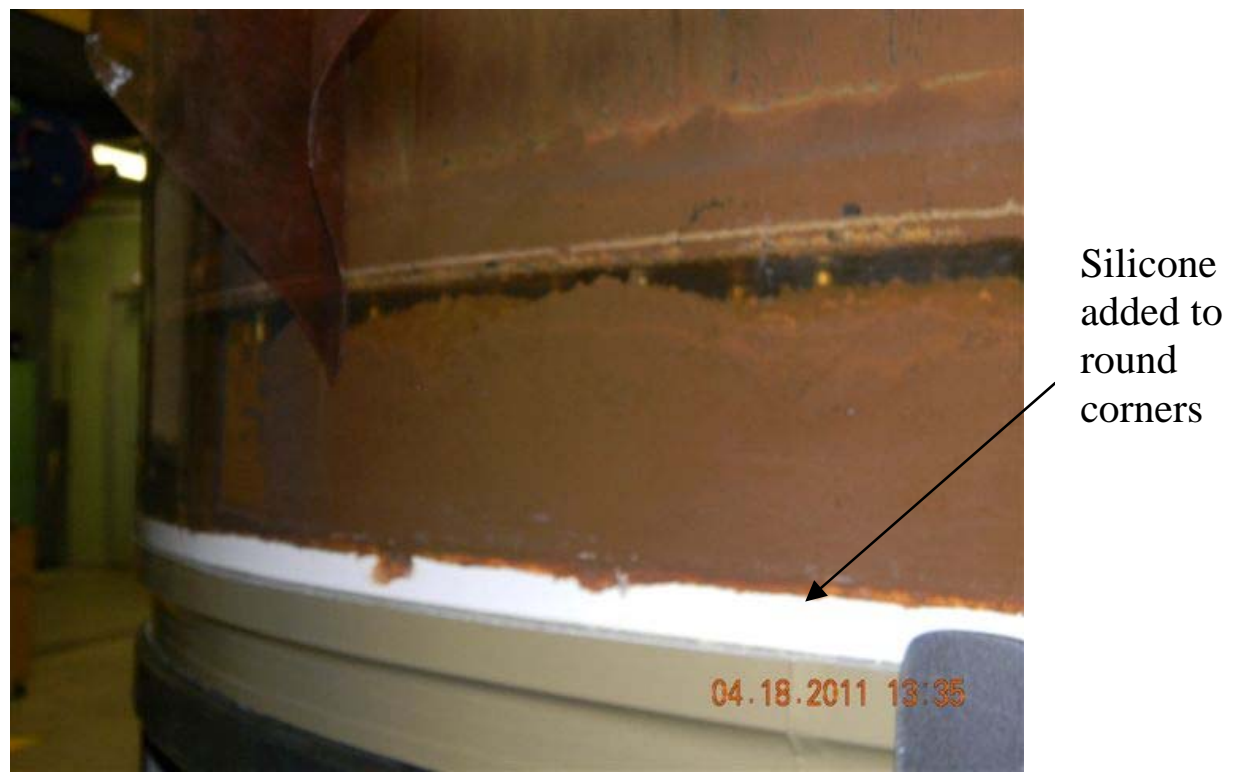

Figure 6. Sludge in Pilot-Scale Tank After Settling 2.5 Weeks

Table 3. Number of Spots in Selected Regions on Tank Bottom

Octant Number of Spots

26

34

$4 \quad 8$

$5 \quad 45$

64

$7 \quad 6$

$8 \quad 6$




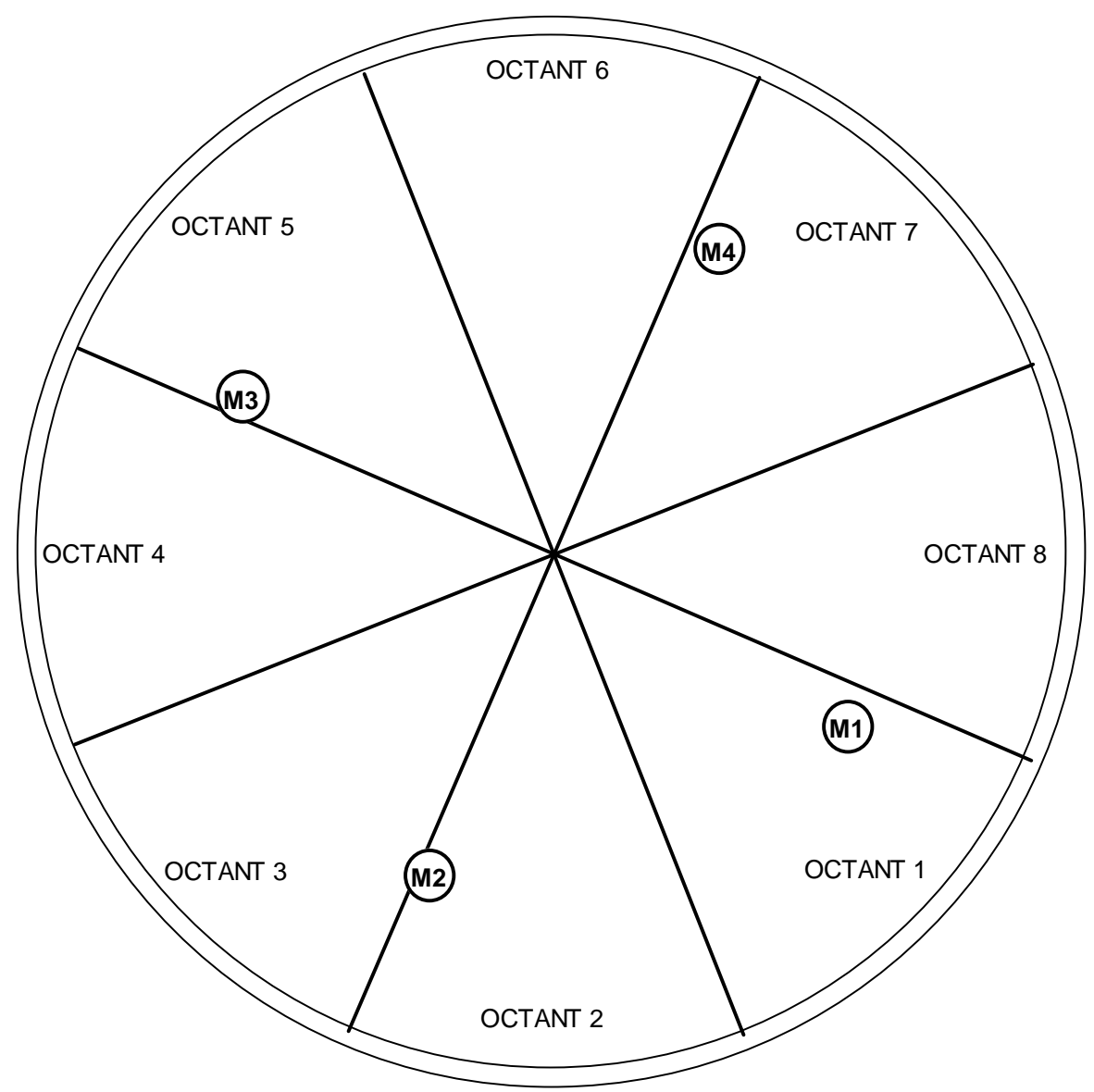

Figure 7. Octants on Tank Bottom

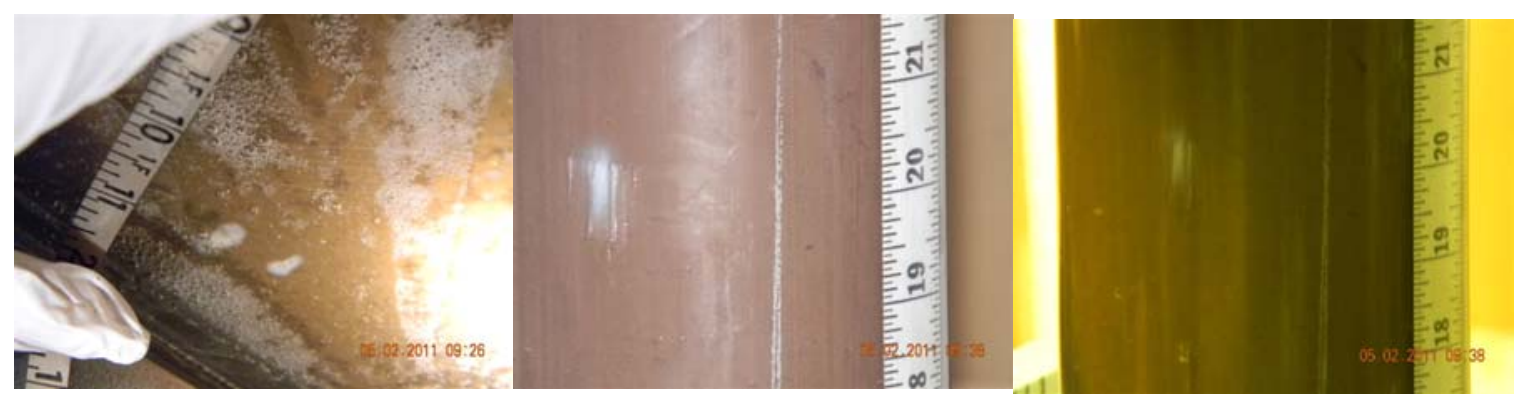

Figure 8. Spots on Tank Bottom After Settling for Four Weeks 


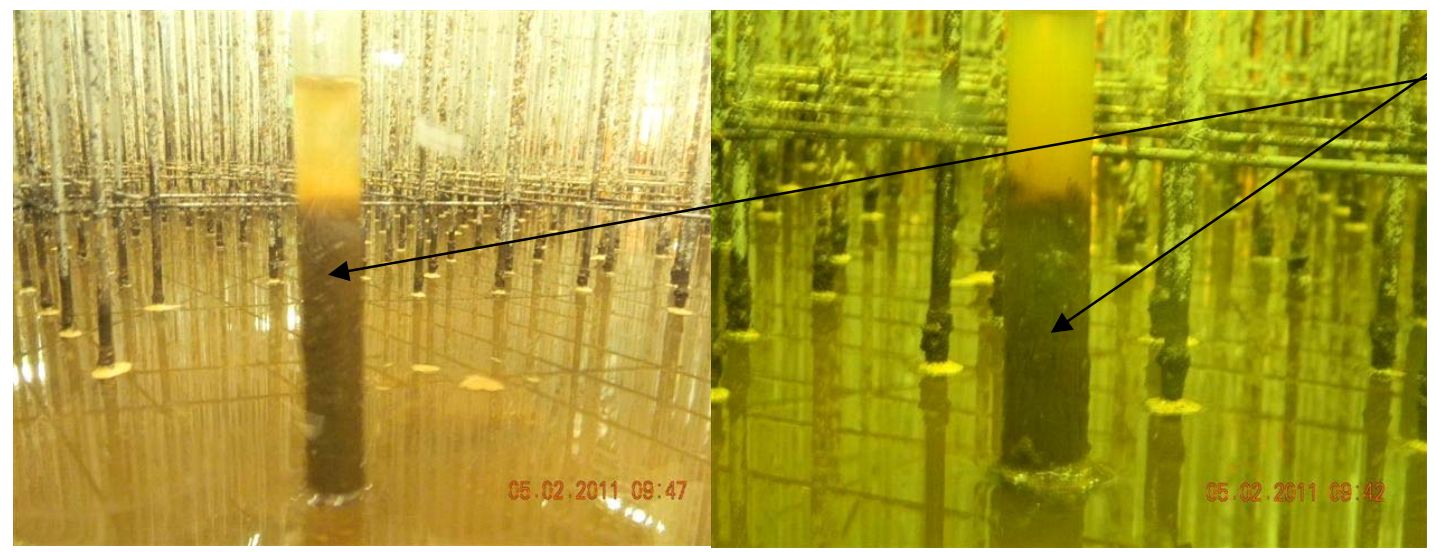

Sampler

Figure 9. Depth Samples After Settling for Four Weeks

\subsection{SOLIDS RESUSPENSION TEST WITH THREE PUMPS}

After settling for four weeks at $45{ }^{\circ} \mathrm{C}$, the sludge, MST, and CST were not effectively mixed with the equivalent of three standard slurry pumps. With the equivalent of three standard slurry pumps $\left(1.22 \mathrm{ft}^{2} / \mathrm{s}\right)$, the effective cleaning radius of the pumps was $24-31$ inches versus a target of 59 inches. The target cleaning radius is determined by the distance from Pump 2 or Pump 4 and the midpoint between the two pumps on the tank wall behind Pump 3 (see Figure 3). At a $\mathrm{U}_{0} \mathrm{D}$ of $1.42 \mathrm{ft}^{2} / \mathrm{s}$ (approximately $72 \%$ of a Quad Volute pump), the entire tank was in motion. However, the quadrant of the tank containing riser B6 and pump M3 (i.e., the pump that was not operating) was not moving vigorously. In addition, a number of white spots ( $<1 / 4 \mathrm{inch}$ in size) were observed that were not moving vigorously. Table 4 shows the number of spots in each of the eight sections under the tank.

\section{Table 4. Number of Spots in Selected Regions on Tank Bottom During Mixing}

\section{Octant $\quad$ Number of Spots}

$\begin{array}{ll}1 & 0 \\ 2 & 4 \\ 3 & 0 \\ 4 & 5 \\ 5 & 25 \\ 6 & 1 \\ 7 & 5 \\ 8 & 4\end{array}$

A large number of spots were observed in octant 5 (the octant with the pump not operating). While the spots occupy a small fraction of the tank bottom, they are indicative of a potential problem. Because the pumps only achieved $70 \%$ of the maximum discharge velocity of a fullscale Quad Volute pump, researchers extrapolated the data to assess the potential to suspend all of the solids with three Quad Volute pumps.

Previous SRNL and PNNL work showed the cleaning radius or zone of influence of a rotating slurry pump to be proportional to the $\mathrm{U}_{0} \mathrm{D}$ of the pump. ${ }^{10,9}$ Since the effective cleaning radius of the pumps was $28-35$ inches at $1.35 \mathrm{ft}^{2} / \mathrm{s}$, the expected cleaning radius at $2.0 \mathrm{ft}^{2} / \mathrm{s}$ (maximum 
$\mathrm{U}_{0} \mathrm{D}$ of a pilot-scale Quad Volute pump) would be 41 - 52 inches. Therefore, three Quad Volute pumps do not provide sufficient power to mix the MST and CST with the sludge.

Figure 10 shows the measured cleaning radius along each of the radial lines. The data show complete cleaning along each of the radial lines at $\mathrm{U}_{0} \mathrm{D}$ of $1.4 \mathrm{ft}^{2} / \mathrm{s}$. The solid line shows a linear fit of the data. The cleaning radii show a linear pattern with $\mathrm{U}_{0} \mathrm{D}$ and show similar cleaning radii at the same $\mathrm{U}_{0} \mathrm{D}$.

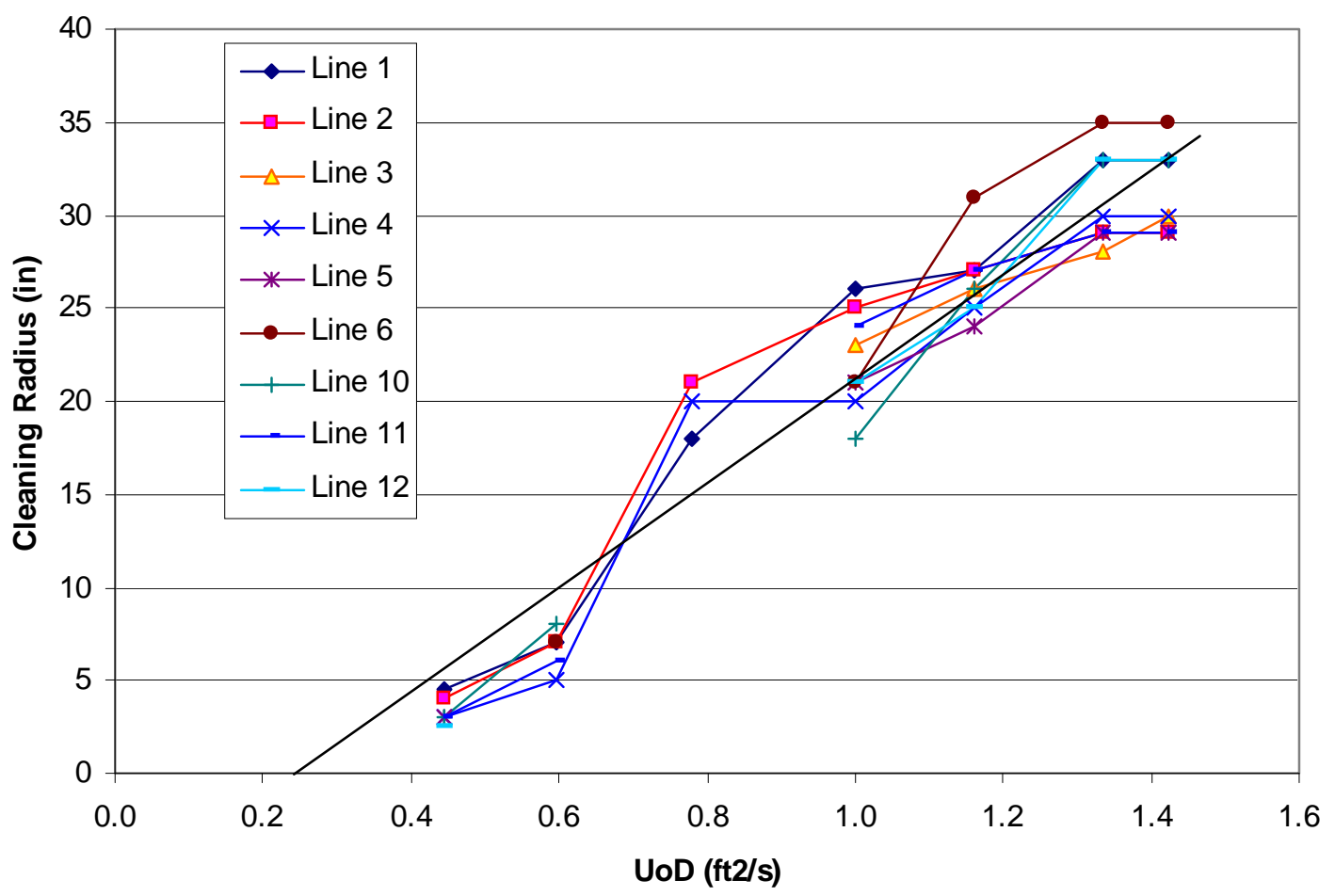

Figure 10. Cleaning Radius Along Each of the Radial Lines in the Three Pump Sludge Resuspension Test

\subsection{SOLIDS RESUSPENSION TEST WITH FOUR PUMPS}

The sludge, MST, and CST were not effectively mixed with the equivalent of four standard slurry pumps. With the equivalent of four standard slurry pumps $\left(1.22 \mathrm{ft}^{2} / \mathrm{s}\right)$, the effective cleaning radius of the pumps was 28 - 34 inches versus a target of 36 inches. The target cleaning radius is the maximum length of the radial lines in Figure 3 . At a $\mathrm{U}_{0} \mathrm{D}$ of $1.35 \mathrm{ft}^{2} / \mathrm{s}$ for each pump (approximately 68\% of a Quad Volute pump), the entire tank was in motion. However, a number of white spots ( $<1 / 4$ inch in size) were observed that were not moving vigorously. Table 5 shows the number of spots in each of the eight sections under the tank. There are fewer spots after mixing with four pumps than after mixing with three pumps. These spots are a small fraction of the tank bottom.

The required $\mathrm{U}_{0} \mathrm{D}\left(1.35 \mathrm{ft}^{2} / \mathrm{s}\right)$ is $111 \%$ of the maximum $\mathrm{U}_{0} \mathrm{D}$ of a standard pump. Therefore, four standard pumps are marginal for mixing and resuspending the MST and CST with the sludge after settling for four weeks at $45{ }^{\circ} \mathrm{C}$. The required $\mathrm{U}_{0} \mathrm{D}$ is a strong function of the sludge shear 
strength. If the shear strength increases, the required $\mathrm{U}_{0} \mathrm{D}$ increases. If the shear strength decreases, the required $\mathrm{U}_{0} \mathrm{D}$ decreases.

Table 5. Number of Spots in Selected Regions on Tank Bottom

Octant Number of Spots

$1 \quad 0$

29

30

$4 \quad 2$

$5 \quad 2$

$6 \quad 0$

$7 \quad 3$

$8 \quad 3$

Figure 11 shows the measured cleaning radius along each of the radial lines. The data show line 6 is the limiting line for complete tank coverage. The data show complete cleaning along each of the radial lines at $\mathrm{U}_{0} \mathrm{D}$ of $1.35 \mathrm{ft}^{2} / \mathrm{s}$. The cleaning radii are linear with $\mathrm{U}_{0} \mathrm{D}$ and approximately equal.

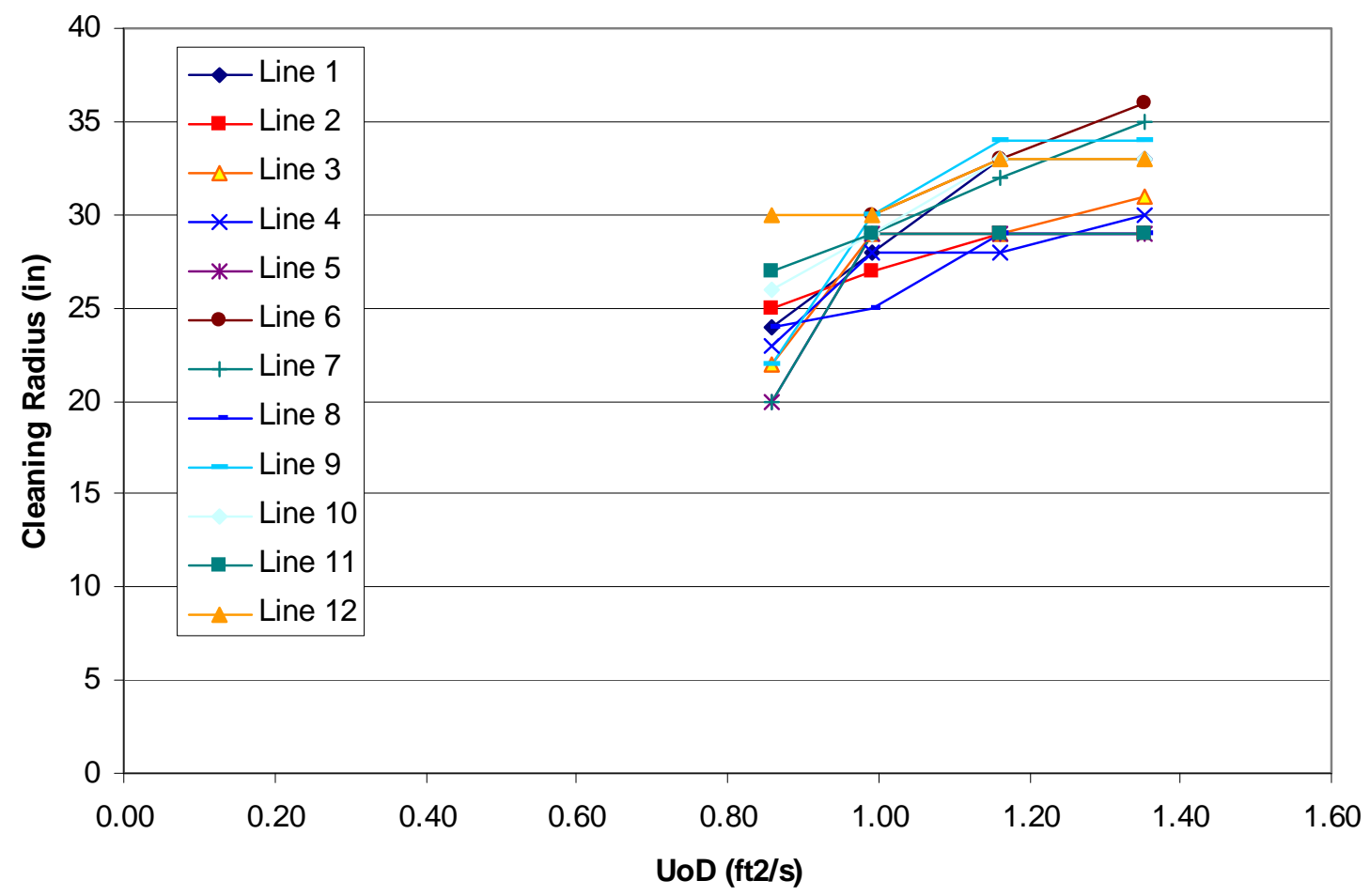

Figure 11. Cleaning Radius Along Each of the Radial Lines in the Four Pump Sludge Resuspension Test 


\subsection{TALL COLUMN TEST}

Figure 12 shows some photos of the tall column during testing. Researchers collected pictures from each of the sections of the column each working day, and reviewed the pictures to look for signs of segregation or preferential settling. The figure shows a "floating" sludge layer. No segregation of solids was observed during four weeks of settling.

Researchers also recorded the height of the bottom sludge layer daily. Initially, the bottom layer settled $3-4$ inches per day. After two weeks, the settling rate decreased to approximately one inch per day.

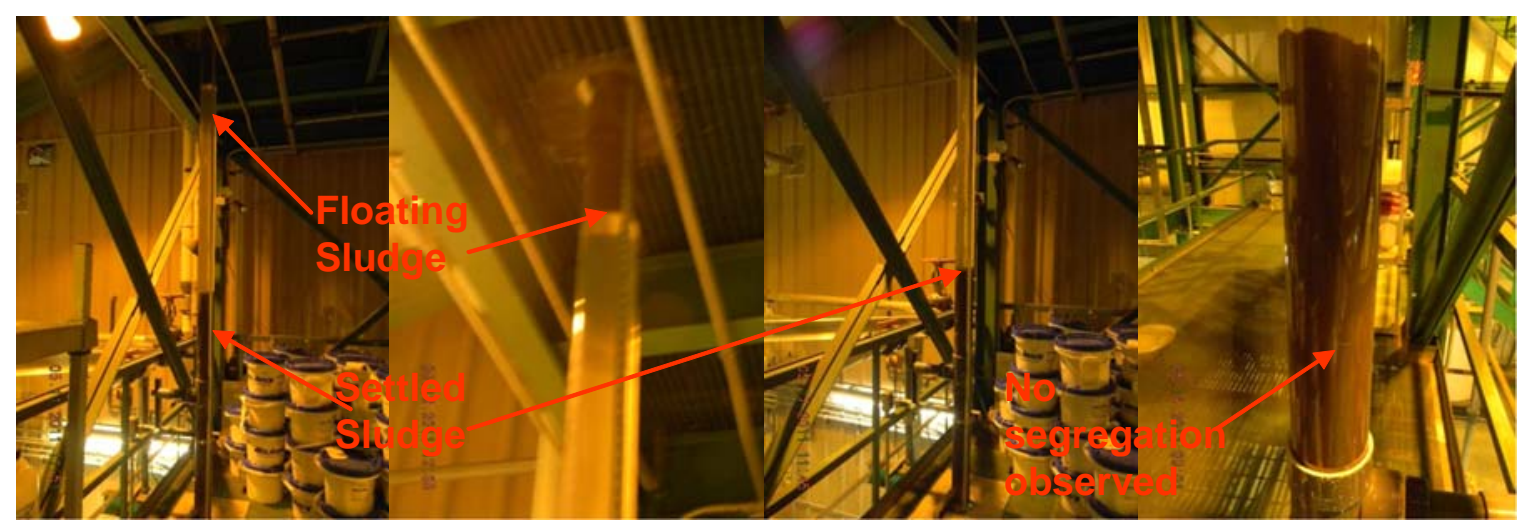

Figure 12. Settled Sludge in Tall Column

\subsection{CONCLUSIONS}

The conclusions from this analysis follow:

- If MST, CST, and simulated sludge particles are well mixed in a sludge tank prior to settling, no preferential settling or segregation is observed over four weeks at $45^{\circ} \mathrm{C}$.

- Four Quad Volute pumps have the power to disperse MST and CST in sludge that has been mixed.

- Four standard pumps are marginal for dispersing the MST and CST in sludge that has been mixed.

- Three standard pumps are not sufficient to mix MST and CST with sludge after settling for four weeks at $45^{\circ} \mathrm{C}$.

- Three Quad Volute pumps did not mix and resuspend MST and CST with sludge after settling for four weeks at $45^{\circ} \mathrm{C}$. Even though the pumps were not able to achieve the maximum discharge velocity of a Quad Volute pump, extrapolation of the data shows three Quad Volute pumps do not have the power to mix and resuspend MST and CST.

- Four standard pumps are marginal for mixing and resuspending MST and CST with sludge after settling for four weeks at $45^{\circ} \mathrm{C}$.

- Four Quad Volute pumps provide the power needed to mix and resuspend MST, CST, and simulated sludge solids that settle for four weeks at $45^{\circ} \mathrm{C}$ in a sludge tank.

- The ability of pumps to disperse MST and CST with sludge is a strong function of the sludge shear strength and yield stress. An increase in shear strength or yield stress leads 
to an increase in the $\mathrm{U}_{0} \mathrm{D}$ needed to mix the slurry. A decrease in shear strength or yield stress leads to a decrease in the $\mathrm{U}_{0} \mathrm{D}$ needed to mix the slurry.

- The tall column test showed no evidence of segregation or preferential settling of the MST and CST particles.

\subsection{RECOMMENDATIONS}

The authors make the following recommendations for pilot-scale testing to support the SCIX process.

- Conduct a test with simulated salt solution and MST in which the salt solution is removed from the tank in a manner that is prototypic of the manner in which it is fed to the RMF. This test will determine the size and location of the heel remaining in Tank $41 \mathrm{H}$ following a SCIX batch.

- Conduct an integrated test with the pilot-scale waste tank and the RMF in which the pilot-scale tank provides the feed to the RMF. The test will provide a more representative feed to the RMF than the 70 gallon feed tank used in previous testing.

\subsection{REFERENCES}

${ }^{1}$ K. M. L. Taylor-Pashow, M. R. Poirier, Z. Qureshi, F. F. Fondeur, T. B. Peters, D. T. Hobbs, and S. D. Fink, “Task Technical and Quality Assurance Plan for Testing to Support Modular Salt Processing Project - Monosodium Titanate Studies”, SRNL-RP-2010-00686, Rev. 2.

${ }^{2}$ M. R. Poirier, Z. H. Qureshi, M. L. Restivo, T. J. Steeper, M. R. Williams, "Investigating Suspension of MST Slurries in a Pilot-Scale Waste Tank”, SRNL-STI-2010-00793, January 24, 2011.

${ }^{3}$ M. R. Poirier, Z. H. Qureshi, M. L. Restivo, T. J. Steeper, M. R. Williams, "Investigating Suspension of MST, CST, and Simulated Sludge Slurries in a Pilot-Scale Waste Tank”, SRNLSTI-2011-00250, May 24, 2011.

${ }^{4}$ Leishear, R. A., Fowley, M. D., and Poirier, M. R., "SDI, Blend and Feed Blending Pump Design, Phase 1”, Savannah River National Laboratory, SRNL-STI-2010-00054.

${ }^{5}$ Herman, D. T. and Poirier, M. R., "Recipe for Simulated Sludge Batch 6-DS for Rotary Filter Testing”, SRNL-TR-2009-00111, Rev. 1, October 2009.

${ }^{6}$ R. A. Leishear, M. R. Poirier, and M. D. Fowley, "Blending Study for SRR Salt Disposition Integration: Tank 50H Scale Modeling and Computer Modeling for Blending Pump Design, Phase 2”, SRNL-STI-2011-00151, May 26, 2011

${ }^{7}$ M. R. Poirier, C. E. Ferguson, D. C. Koopman, and T. B. Edwards, "Rheology of Settled Solids in Small Column Ion Exchange Process”, SRNL-STI-2011-00311, June 20, 2011.

${ }^{8}$ M. R. Poirier and Z. Qureshi, "Scaling Jet Mixing of MST-Containing Solids in the Small Column Ion Exchange Process”, SRNL-STI-2010-00792.

${ }^{9}$ M. R. Powell, Y. Onishi, and R. Shekarriz, "Research on Jet Mixing of Settled Sludges in Nuclear Waste Tanks at Hanford and Other DOE Sites: A Historical Perspective”, PNNL-11686, September 1997.

${ }^{10}$ B. V. Churnetski, “Effective Cleaning Radius Studies”, DPST-81-282, February 19, 1981. 